\title{
Disease incidence of Monilinia fructigena coupled with codling moth damage and mechanical injury in an organic apple orchard
}

\author{
Holb, I.J. \\ Centre of Agricultural Sciences, Institute of Horticulture, University of Debrecen 138 Böszörményi St., \\ 4032 Debrecen, Hungary
}

\begin{abstract}
Summary: In a two-year-study, disease incidence of Monilinia fructigena were quatified and the importance of certain fruit wounding agents was determined. The first infected fruits were observed at the beginning of August in 2011 and 2012. Disease development was continuous until fruit harvest in both years. Pre-harvest yield loss caused by M. fructigena amounted on average $26.3 \%$ in 2011 and $40.4 \%$ in 2012 by fruit harvest. All infected fruits were injured mainly by mechanical injury factors and codling moth (Cydia pomonella). In this study, the most important wounding agents were codling moth and mechanical injury factors in organic apple orchards. In both years, our results showed that $65-75 \%$ of the infected fruits were damaged by codling moth in organic apple production. Moreover, $5-15 \%$ of the infected fruits were mechanically injured in the two years. Our results indicated that most of the damaged fruits fell on the orchard floor before harvest and they became an important secondary inoculum source of $M$. fructigena. Biological and practical implications of the results are discussed.
\end{abstract}

Keywords: brown rot, disease incidence, Monilinia spp., organic apple, wounding agents

\section{Introduction}

Monilinia fructigena (Aderh. \& Ruhl.) Honey is an important pathogen causing fruit rot in apple orchards. Losses caused by $M$. fructigena are usually low in conventional and integrated apple orchards (Moore, 1950; Berrie, 1989; Falconi and Mendgen, 1994; van Leeuwen et al., 2000, 2002; Xu and Robinson, 2000; Holb and Scherm, 2007, 2008; Holb, 2008; Holb et al., 2011). Moore (1950) recorded an average of about $9 \%$ of apple fruits becoming infected with $M$. fructigena during the growing season in conventional apple orchards. In a seven-year-study, Berrie (1989) reported mean post-harvest losses in cultivar Cox's Orange Pippin that ranged from $0.1 \%$ to $0.6 \%$ in integrated apple orchards. Van Leeuwen et al. (2000) demonstrated that pre-harvest disease incidence was 4.2-4.3\% in cultivar James Grieve in 1997 and 1998, in cultivar Cox's Orange Pippin this was $4.4 \%$ in 1997 and $2.7 \%$ in 1998. Post-harvest yield loss amounted on average 1.5-2.0\% for both cultivars. Holb and Scherm (2007, 2008), Holb (2008) and Holb et al. (2011) reported a less than 5\% disease incidence of brown rot of apple by harvest. On the other hand the same authors showed that brown rot incidence can reach $40 \%$ in an organic apple orchards where insect control is not appropriate.

$M$. fructigena penetrates on pre-existing wounds in the fruit skin, although uninjured, ripe apples have been successfully infected via lenticels (Horne, 1933). Many wounding agents are likely to be responsible for fruit injury in pome fruit orchards, such as aboitic and mechanical factors, codling moth (Cydia pomonella), common earwig (Forficula auricularia), blackbirds (Tordus merula) (Croxall et al., 1951; Lack, 1989; van Leeuwen et al., 2000; Xu and Robinson, 2000; Holb and Scherm, 2008, Holb et al., 2008).

The aim of this study was to quantify the disease incidence of M. fructigena in organic apple orchards and to determine the importance of some injury factors such as mechanical injury and codling moth.

\section{Materials and Methods}

\section{Orchard site and plant material}

The study was prepared in an organic apple orchard at Eperjeske, Eastern Hungary. The 5 ha experimental orchard was treated by approved fungicides (copper and wettable sulphur) and insecticides (e.g. Bt products) according to the Hungarian organic production guidelines. The orchard was planted in 1997. Trees were grafted on M26 rootstock and trees were planted with a spacing of $2 \times 5 \mathrm{~m}$. Assessments were made on cultivar Mutsu.

\section{Assessments}

Disease incidence of $M$. fructigena was assessed on fruit from 15 May till 30 September in 2001 and 2002. Assessments were made in every two weeks and on all 
fruits of $4 \times 10$ selected trees. Both the fruits on the trees and the fallen fruits on the orchard floor were assessed and counted. Percentage of disease incidence of $M$. fructigena was calculated for each assessment date. Injury caused by $C$. pomonella and mechanical injury were also assessed on each infected fruit and incidences were calculated.

\section{Data analysis}

Seasonal progress disease incidence of $M$. fructigena, percentage of $C$. pomonella damage on fruit and percentage of mechanical injury on fruit were put into the same a graph separately for 2011 and 2012. All data were subjected to analyses of variance (ANOVA) in order to test the difference of disease development between the two years. Significant F-tests $(\mathrm{P}<0.05)$ were performed for pairwise comparison of the two years' disease development means.

\section{Results and Discussion}

\section{Disease incidence of brown rot}

The first infected fruits were observed at the beginning of August and disease development was continuous until harvest in both years (Figures 1 and 2). Disease incidence was $26.3 \%$ in 2011 and $40.4 \%$ in 2012 by fruit harvest. During the observed period, the speed of disease development was almost one and a half times more in 2012 compared to 2011. Significant F-test $(\mathrm{P}<0.05)$ showed that disease development in 2011 was not significantly different from that of 2012 until the assessment date of 15 August $(\mathrm{P}=0.785)$. However, the disease development was significantly higher in 2012 compared to that of 2011 after the assessment dates of 30 August, 14 and 30 September $(\mathrm{P}=0.045, \mathrm{P}=0.036$ and $\mathrm{P}=0.011$ ).

\section{Incidence of codling moth and mechanical injury on fruit}

All infected fruits were injured by wounding agents probably before infection. From these wounding agents, the C. pomonella and mechanical injury were the most important. The injury caused by $C$. pomonella continuously followed the temporal development of incidence of $M$. fructigena (Figures 1 and 2). However, the level of $C$. pomonella was always lower than the incidence of $M$. fructigena. $65-75 \%$ of the Monilinia infected fruit was damaged by $C$. pomonella. Mechanical injury remained low in both years (Figures 1 and 2). A small increase of mechanical injury was detected at the last assessment date. 5-15\% of the Monilinia infected fruits were mechanically injured in the two years.

This study demonstrated that large amounts of brown rot damage were detected in a Hungarian organic apple orchard in 2011 and 2012. Disease development started at the beginning of August and most of the diseased fruits were injured by larvae of codling moth.

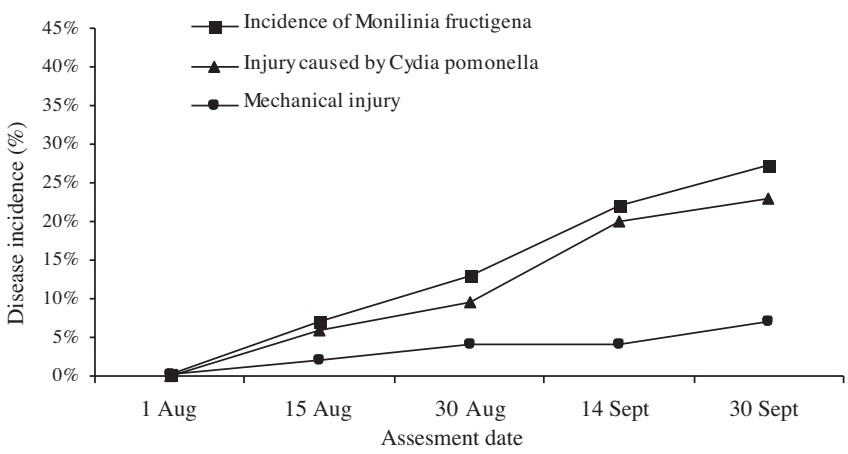

Figure 1. Disease incidence of Monilinia fructigena, incidence of Cydia pomonella damage and of mechanical injury on fruit in an organic apple orchard (Eperjeske, 2011).

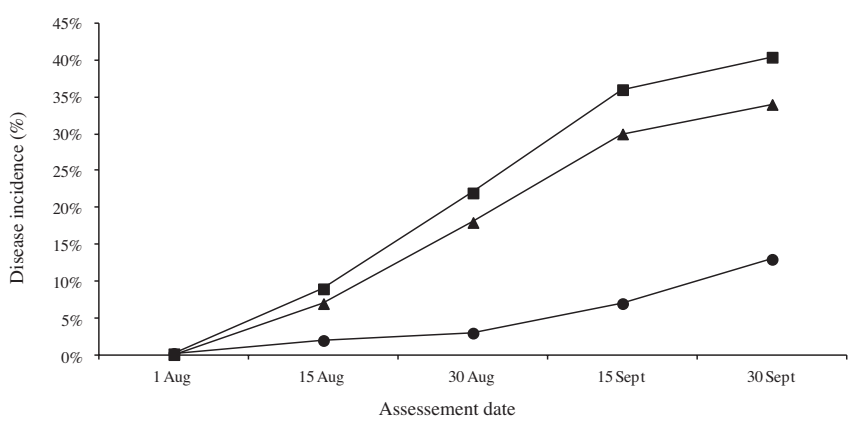

Figure 2. Disease incidence of Monilinia fructigena, incidence of Cydia pomonella damage and of mechanical injury on fruit in an organic apple orchard (Eperjeske, 2012; square = incidence of $M$. fructigena, triangle = incidence of Cydia pomonella, circle = incidence of mechanical injury).

Most infected fruits could be assessed at the second half of the summer and damage greatly increased by harvest in agreement with the studies of Moore (1950), Berrie (1989), Holb (2008). They concluded that the increasing number of Monilinia infected fruits is due to ripening of the fruits and maybe the increasing sugar content of the fruits. However, Croxall et al. (1951), Lack (1989), van Leeuwen et al. (2000), Xu and Robinson (2000) and Holb and Scherm (2008) demonstrated that wounding agents and ripening of the fruits are the main factors determining the amount of infection caused by M. fructigena. Our data support the above statements, because most diseased fruits were assessed around harvest and $65-75 \%$ of the infected fruits were injured by codling moth.

\section{Acknowledgements}

The study was supported by the NKTH programme (OM-00227/2008) and by the research programme of OTKA (K 78399) as well as by a János Bolyai Research Fellowship.

\section{References}

Berrie A. M. (1989): Storage rots of apple and pear in South East England 1980-88: incidence and fungicide resistance. In: Gessler B. K. ed. IOBC Bulletin, Vol. II. Integrated control of pome fruit diseases. Locarno, Switzerland: IOBC, 229-239. 
Croxall H. E., Collingwood C. A. and Jenkins J. E. E. (1951): Obsercation on brown rot (Sclerotinia fructigena) of apples in relation to injury caused by earwigs (Forficula auricularia). Annals of Applied Biology 38: 833-843.

Falconi G. J. and Mendegen D. H. (1994): Epiphytic fungi on apple leaves and their value for control of the post-harvest pathogens Botrytis cinerea, Monilinia fructigena and Penicillium expansum. Journal of Plant Disease and Protection 101(1): 38-47.

Holb, I.J. (2008): Monitoring conidial density of Monilinia fructigena in the air in relation to brown rot development in integrated and organic apple orchards. European Journal of Plant Pathology 120: 397-408.

Holb, I.J., \& Scherm, H. (2007): Temporal dynamics of brown rot in different apple management systems and importance of dropped fruit for disease development. Phytopathology, 97, 1004-1111.

Holb, I.J., \& Scherm, H. (2008): Quantitative relationships between different injury factors and development of brown rot caused by Monilinia fructigena in integrated and organic apple orchards. Phytopathology, 98, 79-86.
Holb IJ, Balla B, Abonyi F, Fazekas M, Lakatos P \& Gáll, JM (2011): Development and evaluation of a model for management of brown rot in organic apple orchards. European Journal of Plant Pathology 129: 469-483.

Lack H. (1989): The spread of apple brown rot (Monilinia fructigena) by insects. Annals of Applied Biology 115(2): 221-227.

Moore M. H. (1950): Brown rot of apples: fungicide trials and studies of the relative importance of different wound-agents. Journal of Horticultural Science 25: 225-234.

Xu X. M. and Robinson J.D. (2000): Edidemiology of brown rot (Monilinia fructigena) on apple: infection of fruits by conidia. Plant Pathology 49(2): 201-206.

Van Leeuwen, G. C. M., Holb, I. J. \& Jeger, M. J. (2002): Factors affecting mummification and sporulation of pome fruit infected by Monilinia fructigena in Dutch orchards. Plant Pathology 51: 787793.

Van Leeuwen G. C. M., Stein A., Holb I., Jeger M. J. (2000): Yield loss caused by Monilia fructigena in Dutch orchards. European Journal of Plant Pathology 75: 534-432. 